\title{
Effect of Blue and Green Light EmittingDiode (LED) on Rat's Retina.
}

\author{
M.I. EL Gohary *,A.E. Ibrahim **,T.M. EL Sayed*,M.M. Gamal **, and M.A. \\ Abu Ghazala *1 \\ *Physics Department, Faculty of Science, Al-Azhar University, 11884 Nasr City, Cairo, \\ Egypt. ${ }^{* *}$ Biophysics and Laser Science Unit, Research Institute of Ophthalmology, \\ Giza, Egypt.
}

\begin{abstract}
Our eyes are increasingly exposed to light from the light emitting diode (LED) of video display terminals (VDT) which contain much blue light. VDTs are equipped with televisions, personal computers, and smart phones.; hence it is so important to know the implications of LED radiations on the human visual system. The present study is designed to evaluate the influence of blue and green LEDs on rat's retina. Forty-six female Wistar albino rats weighing 250-300 g classified into 3 groups. Group (1) served as control. Group (II) exposed to (461 nm) blue LED (12 hr light - dark cycle) for 3, 7, 14 and 21days. Group (III) exposed to (525.9 $\mathrm{nm}$ ) green LED (12 hr light - dark cycle) for 3, 7, 14 and 21days. At the end of each period, electroretinogram (ERG) and microscopic examination are carried out. The results indicated that there was no significant effect for green LED on the ERG, and microscopic examination illustrates mild changes. After exposure of rat's retina to blue LED, there is reduction in aand $b$ - wave amplitudes, and the histopathological examination illustrate severe changes. The data suggest that the blue LED may causes retinal toxicity. Therefore, it is very important to recognize the hazard of LED radiations that affects vision and take appropriate precautions for the eye safetyKeywords:Light emitting diodes, Electroretinogram, histopathological examination.
\end{abstract}

\section{Introduction}

Human visual system is exposed to high levels of natural and artificial lights of different spectra and intensities along lifetime. In the eye, the spectral band of $400-1400 \mathrm{~nm}$ can reach the retina ${ }^{(1)}$. Light less than $400 \mathrm{~nm}$, or more than $1400 \mathrm{~nm}$ are absorbed by the mammalian ocular media, such as aqueous, lens, and vitreous. The retina contains specific chromophores in the photoreceptor (rods and cones) and macular pigments, whose function is to absorb visible radiation to perform vision process.

It was the development in the early 1960 s of a technique for measuring the absorption spectrum of the photopigment contained in a single cone that allowed researchers to confirm the conclusion that Young had reached over a century and a half before. They found that there are three different kinds of cones in the retinas of vertebrates with good color vision, each of the three has a different photopigment with its own characteristic absorption spectrum. As in Fig. (1), some cones are most sensitive to short wavelengths, some are most sensitive to medium wavelengths, and some are most sensitive to long wavelengths.
The main sites of light energy absorption are the melanin pigment granules in retinal pigment epithelial (RPE) cells, which are the first location in the retina to be injured by light exposure ${ }^{(2,3)}$. RPE cells can absorb the electromagnetic visible regionin the range of $380-780 \mathrm{~nm}$. But this luminous energy, necessary for the visual process, can cause a toxic effect, especially the most energetic radiations of the visible spectrum: the violet and blue $(400-500 \mathrm{~nm})^{(4)}$.

Short wavelength light can penetrate through tissues to the cells and their organelles, inducing the generation of reactive oxygen species (ROS) in RPE mitochondria and even apoptosis, potentially caused by ROS-damaged mitochondrial DNA ${ }^{(5)}$.

Recently, Light emitting diodes (LEDs) are long-lived, low heat generating light sources that require little electricity, leading to the increasing widespread use of blue LEDs on liquid crystal displays of electronic devices such as smartphones, computers, and others; so, exposure to LED is increasing ${ }^{(6)}$. 


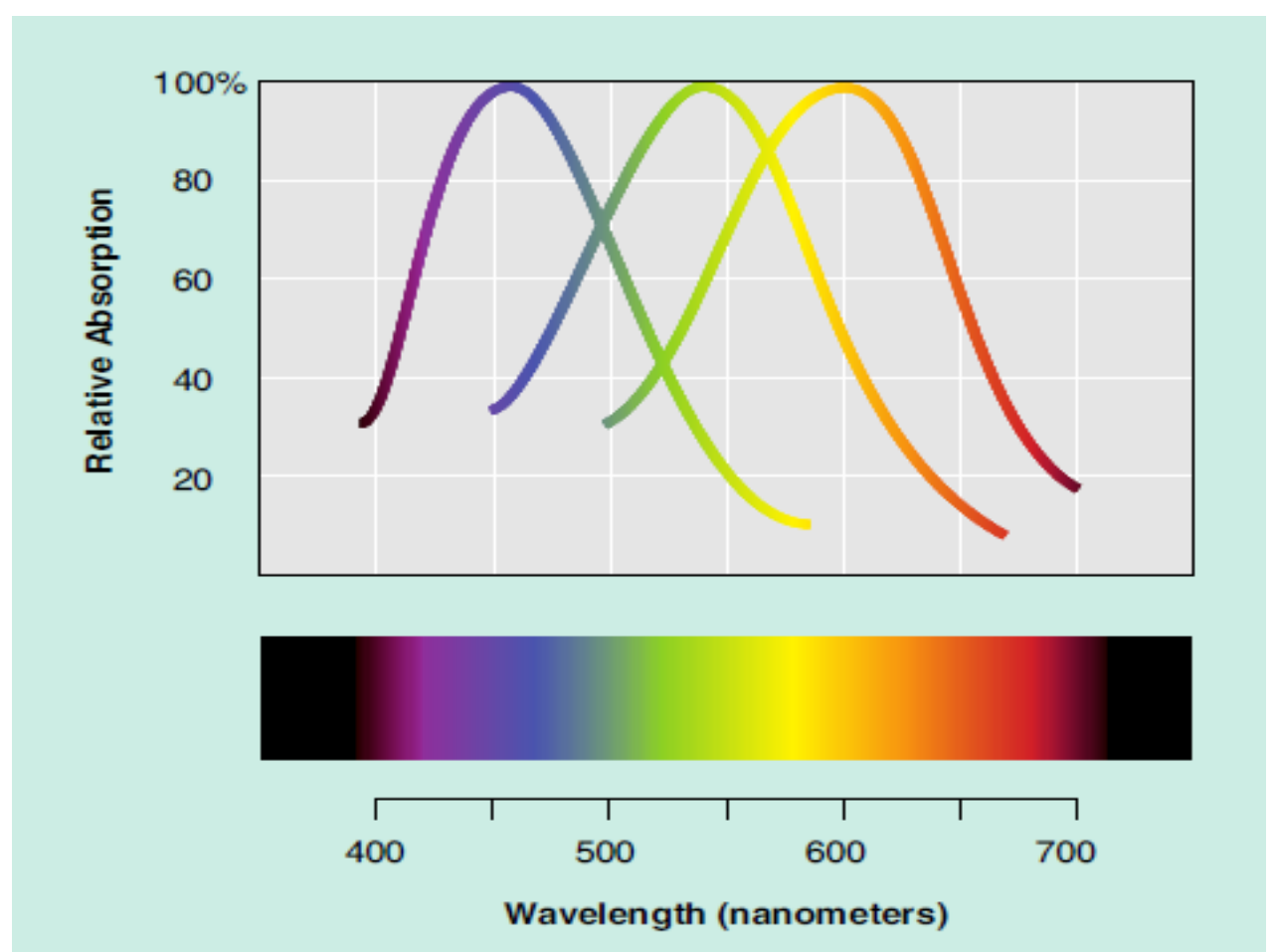

Fig. 1.The absorption spectraof the three classes of cones.

Previous study on animal found thatthe bluerich LED white light has a higher chance to induce photochemical retinal injury (PRI) than does the conventional compact fluorescent lamp (CFL) white light ${ }^{(7)}$. However, susceptibility to PRI is multifactorial ${ }^{(8)}$, and wavelengths certainly play an important role ${ }^{(9)}$.PRIresulting from a cumulative effect is caused by free radicals generated from retinal tissue through continuous light exposure ${ }^{(10)}$. Photochemical retinal damage is induced by chemical reactions initiated by light. When exposure surpasses the protective capability, unfavorable free radicals and reactive oxygen species may form ${ }^{(11)}$.

The aim of the present work is to investigate the effects of different exposure protocols. Twenty-four hours exposure emitted from Viva lamp (V BULB), model E27 (220 V, 9 W, Egypt) is compared to a chronic cyclic (dark/ light) at domestic levels for 3, 7, 14 and 21 days using different LEDs (blue and green).

\section{Material and Methods}

\section{Animals}

Forty-six female Wistar albino rats weighing 250-300 g are selected from the animal house of Research Institute of Ophthalmology, Giza, Egypt.
The rats are maintained in a standard $12 \mathrm{hr}$ light dark cycle with free access to water and balanced diet at a temperature of $22 \pm 2{ }^{\circ} \mathrm{C}, 50 \%$ humidity. All procedures are conducted according to the principles enunciated in the guide for care and use of laboratory animals. The rats are classified into 3 groups according to the following:

Group I: contain six rats and used as control.

Group II: contain 20 rats and subdivide into four subgroups (5 rats, 10 eyes each). All subgroups are exposed to blue light of LED and decapitated after 3, 7, 14 and 21 days respectively.

Group III: contain 20 rats and subdivide into four subgroups (5 rats, 10 eyes each). All subgroups are exposed to green light of LED and decapitated after 3, 7, 14 and 21 days respectively.

\section{Light sources}

Single-wavelength blue LED (461 nm) and green LED (525.9 $\mathrm{nm}$ ) are custom-made for the exposure experiments (Fig. 2). The spectrum distributions and total intensities for all light sources are detected by Ocean Optics USB4000 spectrometer (Detector: Toshiba TCD1304AP linear CCD array, detector range: $200-1100 \mathrm{~nm}$, grating options: 14 gratings $/ \mathrm{mm}$, UV through shortwave NIR, optical resolution: 0.3-10.0 nm FWHM).

Egypt. J. Biophys. Biomed. Engng. Vol. , (2018) 


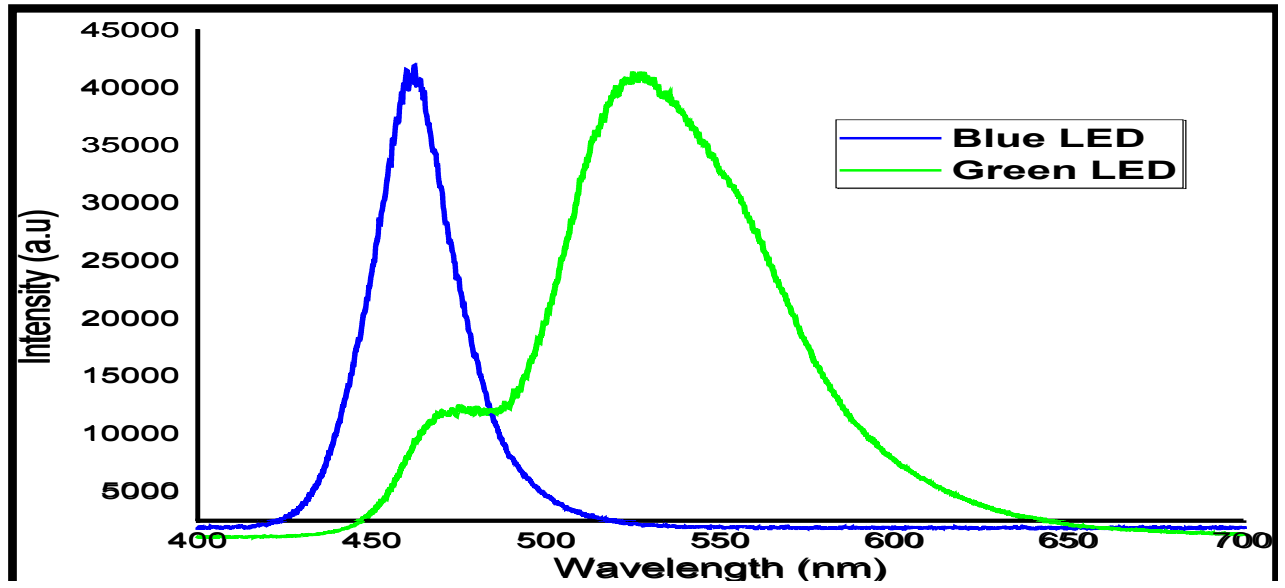

Fig. 2. spectral irradiance of blue and green LED source.

\section{Light exposure}

Each group of rats is maintained in a 12-hours light-dark cycle in transparent poly carbonate cages with dimensions of $(50 \mathrm{~cm} \times 27 \mathrm{~cm} \times 18$ $\mathrm{cm})$. Blue and green light sources \{Viva lamp (V BULB), model E27 (220 V, 9 W, Egypt) $\}$ are set on the top of each cage and are measured $25 \mathrm{~cm}$ away from the rats with total exposure duration of $3,7,14$ and 21 days.

\section{Electroretinography (ERG) \\ Animal preparation}

The animals are dark adapted for 3 hours before the electrophysiological recording. They are anesthetized intramuscularly by xylazine (21 $\mathrm{mg} / \mathrm{kg}$ of body weight) as muscle relaxant, and ketamine hydrochloride $(45 \mathrm{mg} / \mathrm{kg})$. After establishing the anesthesia, animals are placed on the pad of an operating table where their body temperature was maintained at $37{ }^{\circ} \mathrm{C}$. Each rat is positioned with its head resting to one side and local anesthetizing eye drops are also applied. The pupil of the recorded eye is dilated with topical $1 \%$ mydriacyl.

\section{Electrophysiological recording}

A white flash with fixed intensity 4 lux and duration 0.2 sis applied. The electroretinogram is recorded by using sensor PS-2111 and its electrodes (PASCO, Roseville, CA) which connect to PASPORT interface direct to the computer. One electrode is placed at the corneal periphery as active electrode; the other electrode is placed on the skin of the lower eyelid as a reference one. The last electrode is placed on the ear as an earthed one. The electrodes are placed on the skin after removal the hair Fig. (3). The result of electrophysiological signals is collected and analyzed by data studio 1.9.8 software (PASCO, Roseville, CA).

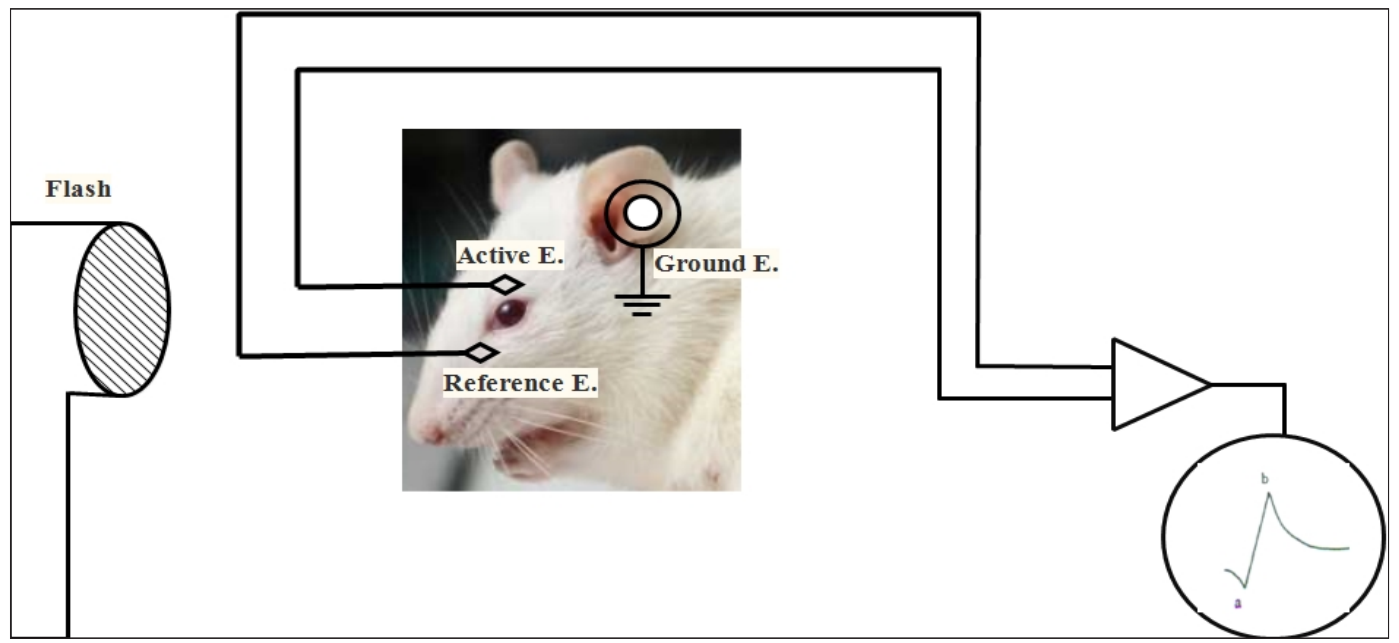

Fig.3. System for recording ERG of rats. 


\section{Histopathological Examination of the Retina}

The eyes were enucleated and intraocular injection of $0.1 \mathrm{M}$ phosphate buffer ( $\mathrm{PH} \mathrm{7.3)}$ containing $5.4 \%$ glucose and $4 \%$ glutaraldehyde was carried out. The cornea and lens were removed and the posterior segment of the eye containing the retina cut into small pieces (about $1 \mathrm{~mm}^{3}$ ) then further fixed for another eight hours in fresh glutaraldehyde buffered solution. The specimens were washed for one hour with several changes of phosphate buffer and dehydrated in cold alcohol series $(50 \%, 70 \%, 80 \%, 90 \%$ and $96 \%$ ) with freshly prepared araldite mixture and the blocks were polymerized at the specimens were then placed in propylene oxide 10 minutes then in Araldite (according to Galbert 1965). The specimens were embedded in rubber boats prefilled at $70^{\circ} \mathrm{C}$ for 48 hours. Semithin sections blocks were sectioned by LKB ultratome, mounted on glass slide and stained with Toluidine blue. The slides are examined by light microscope.

\section{Statistical analysis}

Data are presented as mean $\pm \mathrm{SD}$, data are analyzed by using student t-test and difference between the mean of different groups is considered significant at a level of $\mathrm{p}<0.05$. The statistical program applied is Statistical Package for the Social Sciences (SPSS).

\section{$\underline{\text { Results }}$}

\section{ERG analysis}

The baseline of the ERG is the standing potential of the eye. The amplitude of a-wave is measured from the baseline to the a-wave trough while $b$-wave is measured from the peak of the a-wave to the peak of the b-wave. Typical records of ERG for control group and after exposure to blue and green LED are shown in Fig. (4). The amplitude of a- wave has mean values of 0.958 $\pm 0.029 \mathrm{mV}$ while the $\mathrm{b}$-wave is $1.769 \pm 0.053$ $\mathrm{mV}$ for control group. The obtained data are summarized in Tables ( 1 and 2).

The results indicate that there is no significant effect of green LED on the ERG. After exposure to blue LED, there is reduction in a- and bwave amplitudes, Figs. (5\&6). This reduction is increased with time of exposure in comparison with control group. The percentage change clarified that a-wave is more affected than b-wave (Tables $1 \&$ 2). Moreover, after exposure to blue LED for 21 days, the rat's retinadisplays negative ERG.

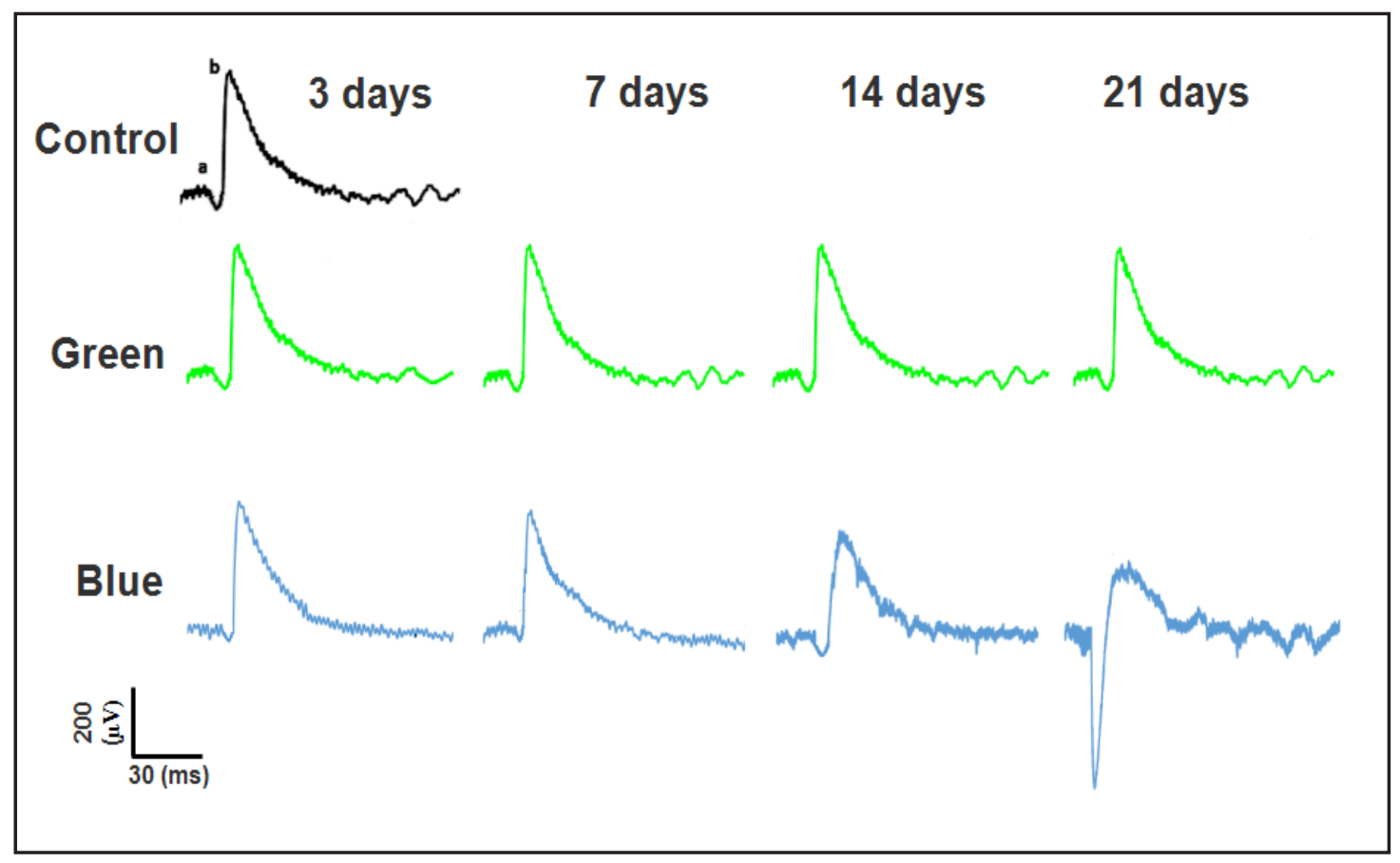

Fig. 4. ERG records of control rats and which exposed to blue and green LED for3,7,14,and 21 days. 
TABLE 1. Amplitude and \% change of a-wave for control and rats exposed to blue and green LEDs.

\begin{tabular}{|c|c|c|c|c|c|c|c|c|}
\hline & \multicolumn{2}{|l|}{$3 \mathrm{D}$} & \multicolumn{2}{|c|}{$7 \mathrm{D}$} & \multicolumn{2}{|c|}{$14 \mathrm{D}$} & \multicolumn{2}{|c|}{$21 \mathrm{D}$} \\
\hline & Mean \pm SD & $\begin{array}{c}\% \\
\text { change }\end{array}$ & Mean \pm SD & $\begin{array}{c}\% \\
\text { change }\end{array}$ & Mean \pm SD & $\begin{array}{c}\% \\
\text { change }\end{array}$ & Mean \pm SD & $\begin{array}{c}\% \\
\text { change }\end{array}$ \\
\hline Control & $0.958 \pm 0.029$ & - & $0.958 \pm 0.029$ & - & $0.958 \pm 0.029$ & - & $0.958 \pm 0.029$ & - \\
\hline Green & $0.951 \pm 0.02$ & $0.7 \%$ & $0.949 \pm 0.013$ & $0.9 \%$ & $0.952 \pm 0.012$ & $0.6 \%$ & $0.946 \pm 0.023$ & $1.3 \%$ \\
\hline Blue & $0.911 \pm 0.019$ & $4.9 \%$ & $0.761 \pm .020$ & $20.6 \%$ & $0.632 \pm 0.012$ & $34 \%$ & $2.700 \pm 0.018$ & $-182 \%$ \\
\hline
\end{tabular}

TABLE 2. Amplitude and \% change of b-wave for control and rats exposed to blue and green LEDs.

\begin{tabular}{|c|c|c|c|c|c|c|c|c|}
\hline & \multicolumn{2}{|c|}{$3 \mathrm{D}$} & \multicolumn{2}{c|}{$7 \mathrm{D}$} & \multicolumn{2}{c|}{$14 \mathrm{D}$} & \multicolumn{2}{c|}{$21 \mathrm{D}$} \\
\hline & Mean $\pm \mathrm{SD}$ & $\begin{array}{c}\% \\
\text { change }\end{array}$ & Mean $\pm \mathrm{SD}$ & $\begin{array}{c}\% \\
\text { change }\end{array}$ & Mean $\pm \mathrm{SD}$ & $\begin{array}{c}\% \\
\text { change }\end{array}$ & Mean $\pm \mathrm{SD}$ & $\begin{array}{c}\% \\
\text { change }\end{array}$ \\
\hline Control & $1.769 \pm 0.053$ & - & $1.769 \pm 0.053$ & - & $1.769 \pm 0.053$ & - & $1.769 \pm 0.053$ & - \\
\hline Green & $1.757 \pm 0.051$ & $1.0 \%$ & $1.749 \pm 0.043$ & $1.1 \%$ & $1.759 \pm 0.022$ & $0.6 \%$ & $1.756 \pm 0.031$ & $0.7 \%$ \\
\hline Blue & $1.735 \pm 0.043$ & $1.9 \%$ & $1.543 \pm 0.033$ & $13 \%$ & $1.341 \pm 0.034$ & $24 \%$ & $3.000 \pm 0.12$ & $-70 \%$ \\
\hline
\end{tabular}

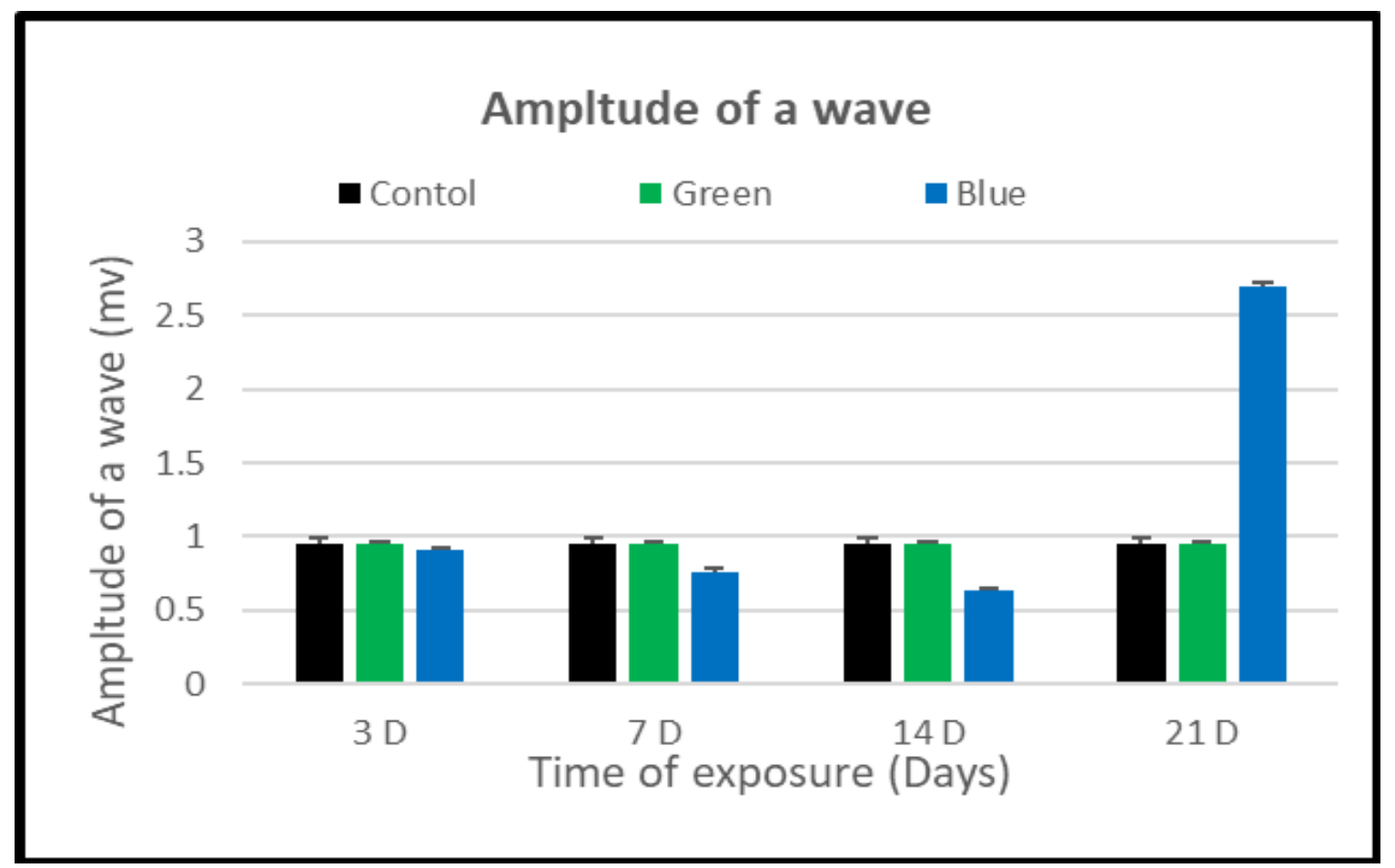

Fig.5. Amplitude of a-wave (mV) of the control and rats exposed to blue and green LED for 3,7,14,and 21 days.

Egypt. J. Biophys. Biomed. Engng. Vol., , (2018) 


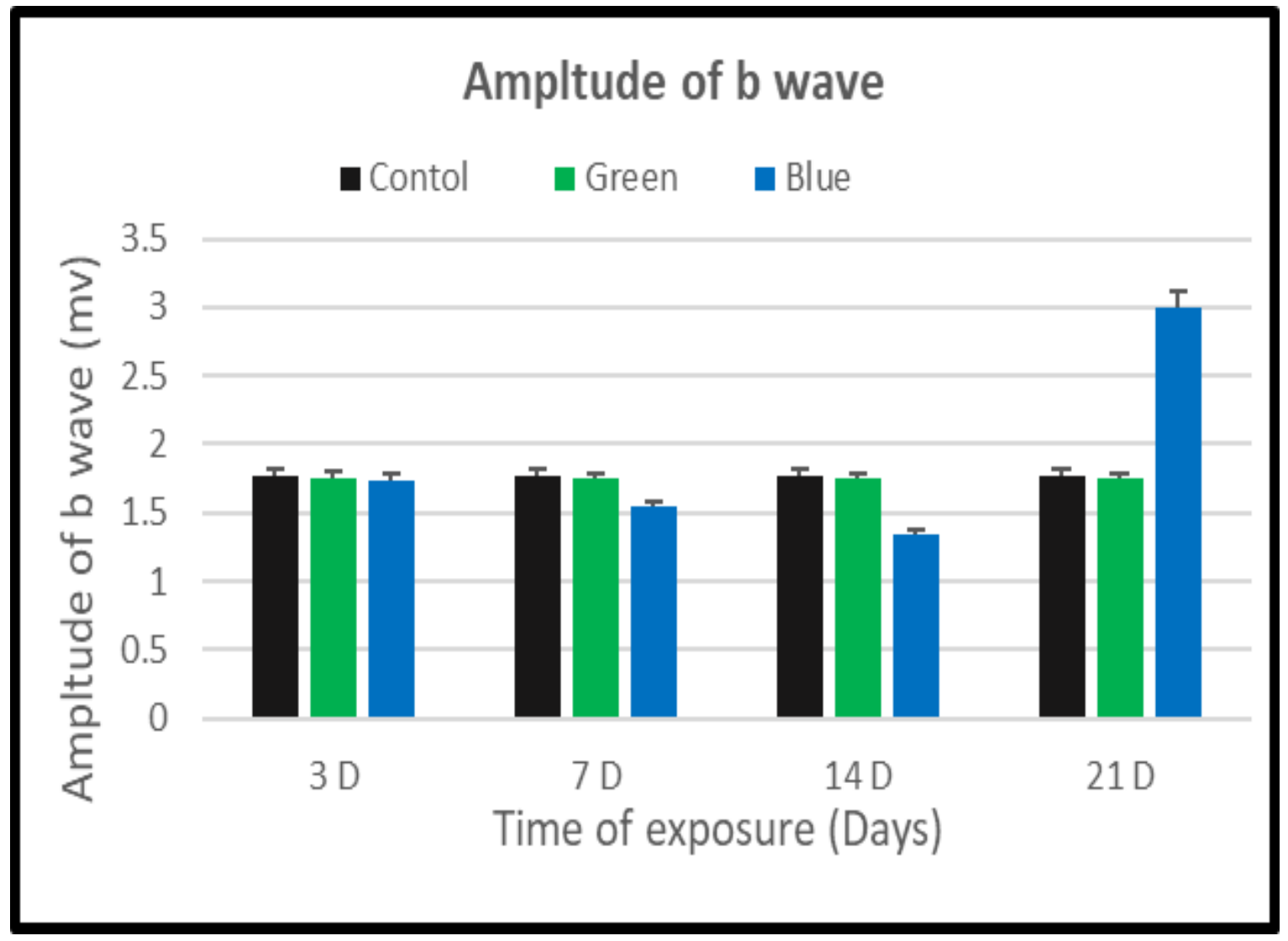

Fig. 6. Amplitude of b-wave ( $\mathrm{mV}$ ) of the control and rats exposed to blue and green LED for 3,7,14, and 21 days.

The $\mathrm{b} / \mathrm{a}$ ratio is serving as a quantitative index and an examination to the vitality of the retina. In the present study, the calculation of $\mathrm{b} / \mathrm{a}$ ratio for control group is 1.85 . For the exposed groups, this ratio showsenhancement throughout the time of experiment performance (Fig.7).

\section{Histological Analysis}

Light microscopic examination of semithin sections forretina of control rat reveals normal histological appearance of layers of the retina extending from outside towards the vitreous (Fig.8 A) as follows: 1- Pigment epithelium layer (PE), 2- Photoreceptor (ph.), 3- Outer limiting membrane (OLM), 4- Outer nuclear (ONL), 5- Outer plexiform (OPL), 6- Inner nuclear (INL), 7- Inner plexiform (IPL), 8Ganglion cells (GCL), 9- Nerve fibre (NFL) and 10- Inner limiting membrane (ILM).
Light microscopic examination of rat's retina exposed to blue LED for 3 days (Fig. 8 B) illustrates mild changes. These changes increase after 7 days (Figs.8 C \&8 D) and 14 days of exposure to blue LED (Figs. 8 E \& 8 F). After 21 days of exposure to blue LED, severe structural changes appear in the pigment epithelium and sensory retina (Figs.8 G \& 8 H).

Light microscopic examination of retina for rats exposed to green LED illustrates mild change in photoreceptors layer. This change increases by enlargementof exposure time. Fig. (9A) illustrates the histological changes of rat retina 3 days post exposure; Fig. (9B \&9C) are after 7 days of exposure to same colour; Fig.(9D) is after 14 days of exposure to same effect in addition to (Figs.9 E \&9F) are after 21 days of exposure to green LED. 


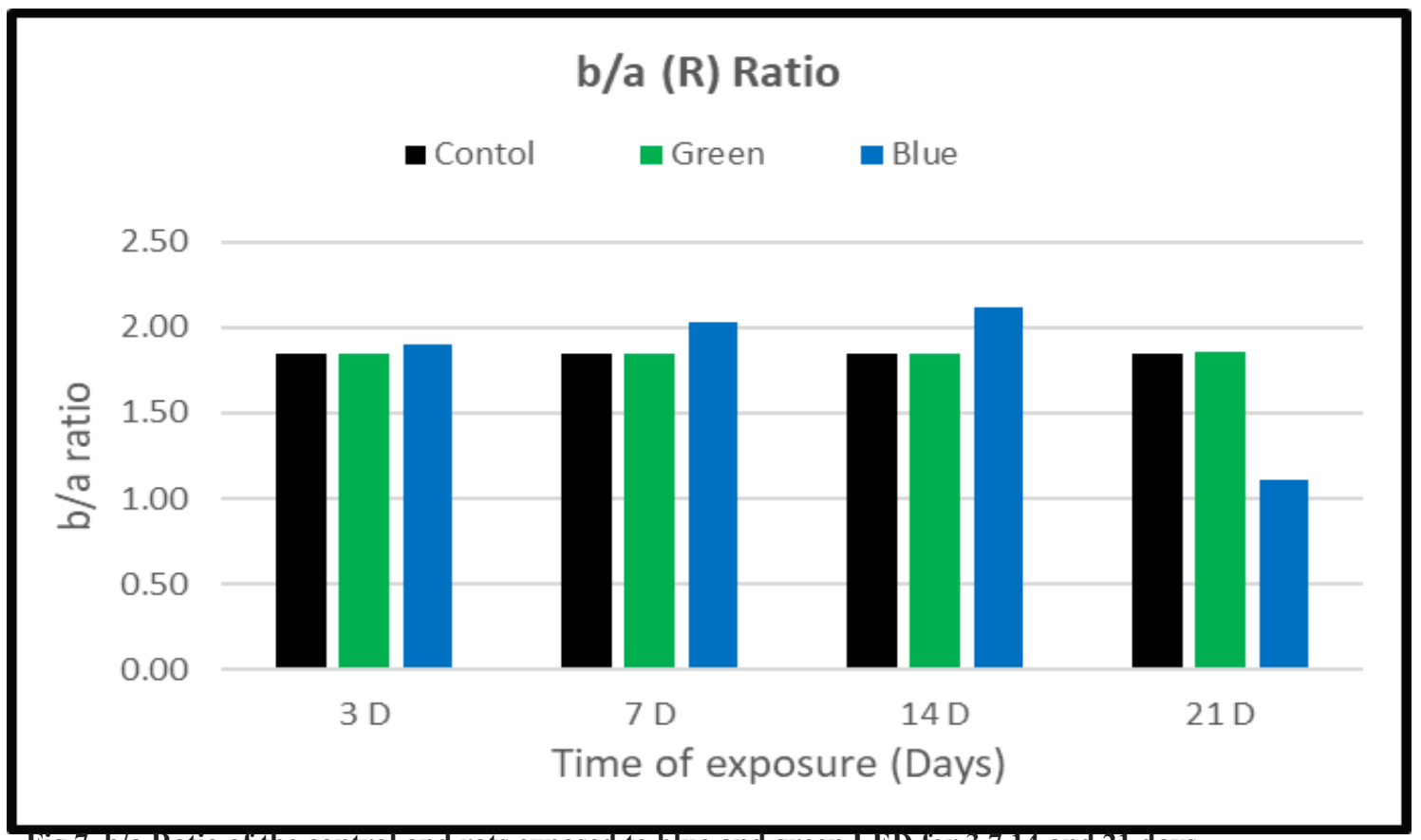

Fig.7. b/a Ratio of the control and rats exposed to blue and green LED for 3,7,14,and 21 days.
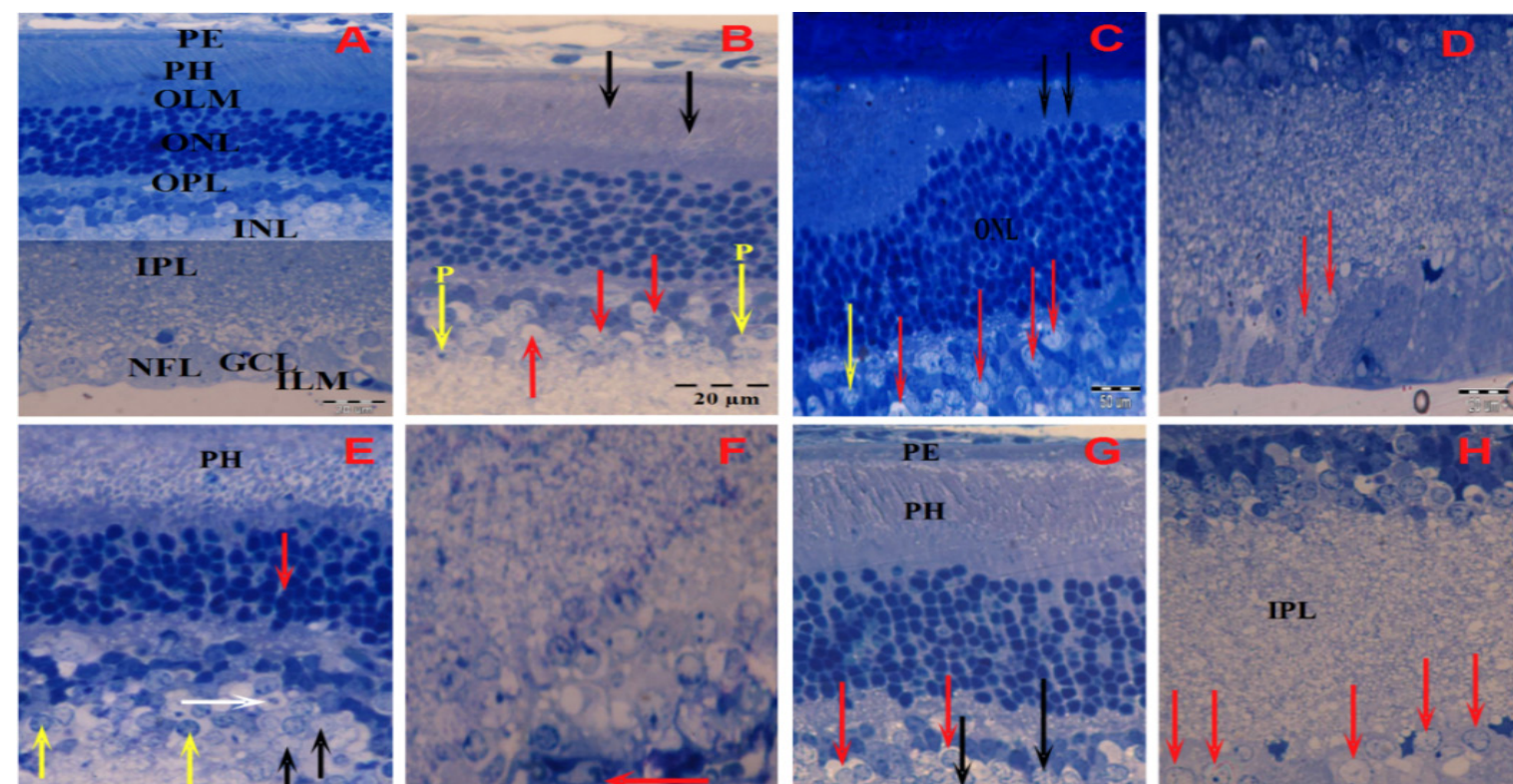

Fig.8. Histological examination of control rat retina and after exposur to blue LED for 3, 7, 14 and 21 days. (A) normal retina layers. (B) Histological examination of rat retina 3 days post exposure to blue LEDshowfragmentation of photoreceptor (black arrows), clear holes around nuclei (red arrows) and few pyknotic nucleiof inner nuclear layer (INL) (yellow arrows). (C): 7 days after exposure to blue LED, there are disorganized photoreceptor (black arrows), the outer nuclear layer (ONL) is of inhomogeneous thickness and many nuclei of inner nuclear layer (INL) illustrate signs of karyolysis(red arrows) and karyorrhexis (yellow arrow). (D): The cytoplasm of the ganglion cells has foamy appearance (red arrows). (E) severe fragmentation of outer and inner segment of photoreceptor and deeply stained nuclei of outer nuclear layer (red arrow). Many nuclei of inner nuclear layer showing clumping of their chromatin (yellow arrows) and other showing signs of karyolysis (blak arrows) with clear holes around the nucleus (white arrow). (F) 14 days after exposure to blue LED, the capillaries in the nerve fiber layer have thick wall (red arrow). (G) The pigment epithelium layer (PE) showing many vacuoles with disintegration of outer and inner segment. The inner nuclear layer showsclumping of their chromatin with clear holes around the cells (red arrows), other cells appeared disintegrated (blak arrows). (H) 21 days after exposure to blue LED, oedema in inner plexiform layer, lysis of nuclei of ganglion cells layer (red arrows) and the ganglion cells appeared faintly stained.

Egypt. J. Biophys. Biomed. Engng. Vol. , (2018) 

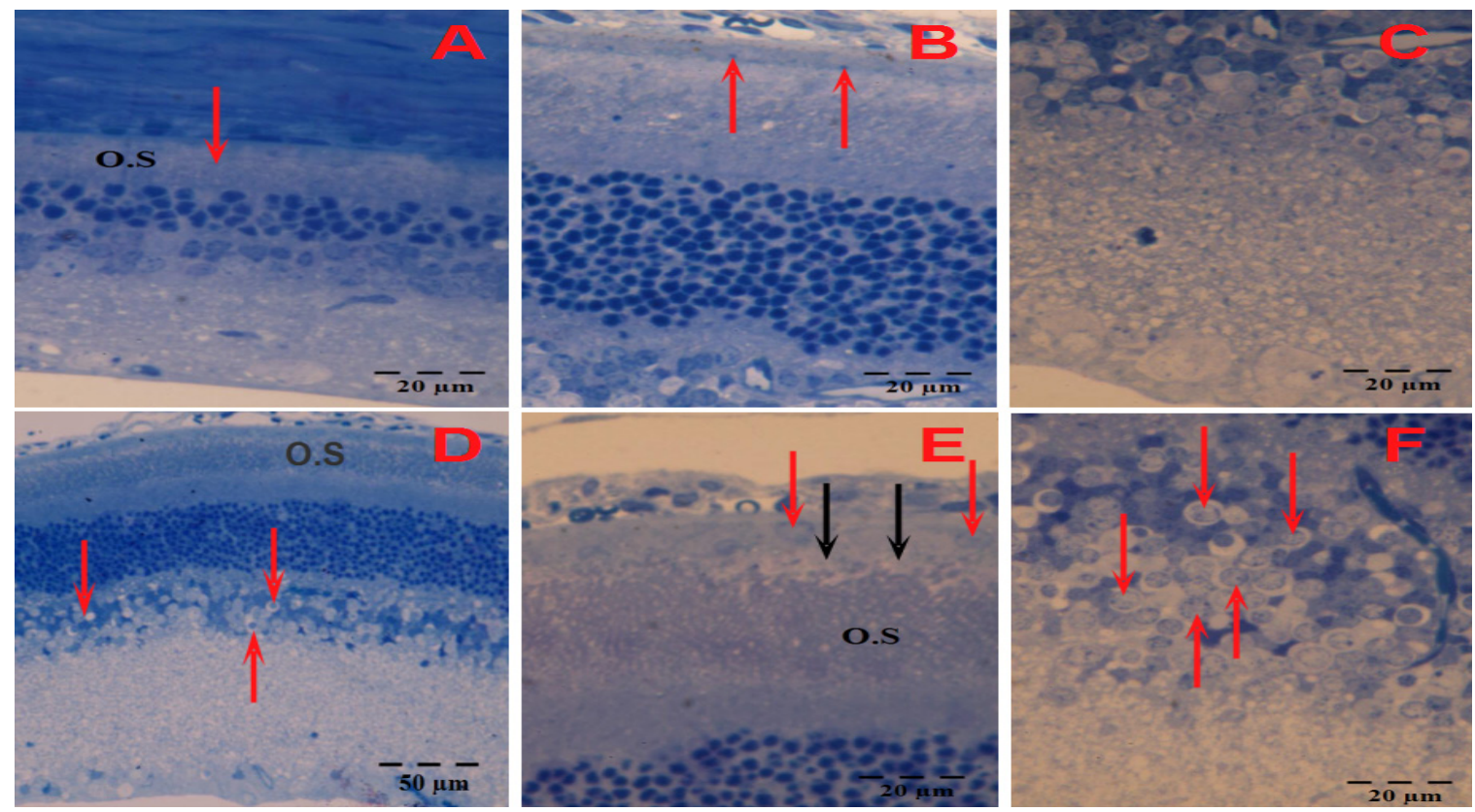

Fig. 9. Histological examination of rat's retina after 3, 7,14 and 21 days of exposure to green $L E D$ analyzed by $H \& E$ staining.(A) Rat's retina after exposure to green LED for 3 days illustrates disorganized outer segments (O.S) of photoreceptor (red arrow). All remaining retinal layer appears more or less preserved. (B): 7 Days after exposure to green LED illustrates densly granules in the PE layer with fragmented outer segments of photoreceptors (red arrow) are shown. (C): No observable changes of inner retinal layers. (D): 14 Days after exposure to same colour illustrates fragmentation of the outer segment $(O . S)$ of photoreceptor with clear hallows (red arrows) around the nuclei of inner layer. (E): 21 Days after exposure to green colour showing slightly separation between (PE) and photoreceptor layer (black arrows), faintly stained nuclei of (PE) layers (red arrows) with fragmentation of outer segment of photoreceptor (O.S).(F): Clear hallows around nuclei of the (INL) (red arrows) with accumulatin of their nuclear chromatin.

\section{Discussion}

Over the recent years, the interest in lightinduced damage to the retina has been revived mostly due to the fact that it resembles many features of retinal degenerative diseases observed in humans, particularly age-related macular degeneration $(\mathrm{AMD})^{(8,12)}$.

In the present work, the ERG records are recorded for female Wistar albino rats before and after 3,7,14 and 21 days of exposure to blue and green LEDs. Histopathological study was achieved for all the above cases to ensure the results. The results show that the obtained ERG waves for control animals consist of the two wellknown waves; namely a- and b- waves. Their amplitudes are used to determine retinal function. However, an additional parameter for the ERG analysis is the $b / a(R)$ value becomes most useful in evaluating the loss of retinal function ${ }^{(13)}$.

Exposure to blue LED, significantly reduced $a-$ and b- wave amplitudes. This reduction is accompanied by an increase in the $(R)$ value
(Fig.7). This behavior is reversed after 21 days of exposure to blue LED where negative ERG is recorded. The above resultsare in agreement with those obtained byYu-Man Shang et al., (2014) ${ }^{(7)}$ who indicated that blue LED group demonstrated a significant decrease of b-wave amplitude in rats at days 9 and 28 of light exposure.

Visible light (400-750 $\mathrm{nm})$, is referred to as short- (blue), medium- (green), and longwavelength (red) region. Blue light (400-500 nm) is the shortest wavelength within the visible light range. According to Planck's relation:

$$
\begin{aligned}
& \mathrm{E}=\mathrm{hv} \quad \text { (1) } \\
& \mathbf{E}=\mathbf{h} \frac{\mathbf{c}}{\lambda} \\
& \mathrm{E} \alpha \frac{1}{\lambda}
\end{aligned}
$$

where $\mathrm{E}=$ (energy) is directlv proportionaltovand is inversely proportionalto $\lambda, \mathrm{h}=\left(6.626 \times 10^{-}\right.$ ${ }^{34} \mathrm{~m}^{2} \mathrm{~kg} / \mathrm{s}$ )the Planck constant, $v$ frequency in 
H.z and $\lambda$ =wavelength, a photon corresponding to blue light is more energeticthan photons of longer wavelengths, such as green. Production of reactive oxygen species increases with decreasing wavelength $^{(4)}$. Blue light-induced oxidative stress is also induced death of photoreceptors ${ }^{(14)}$, and RPE cells ${ }^{(15)}$. Therefore, blue light is considered a risk factor of age-related macular degeneration ${ }^{(16)}$. The exposure to green LED indicates insignificant effects on the ERG record along the whole time of exposure (Fig.4). This finding agrees with Song et al., (2016) ${ }^{(17)}$ who found that the green LED light efficiently reduces retinal damage and stress.

In order to clarify the obtained results, firstly the photochemical damage process should be explained. For a photochemical damage to occur; it is necessary that the light must be transmitted to tissues with high oxygen content and then be absorbed by a chromophore ${ }^{(18)}$. By applying the previously mentioned idea on retina and light photochemical damage will occur. Photochemical damage is theorized to result due to generation of free radicals after exposure. While the retina possesses inherent mechanisms to protect itself against such insult, it is thought that damage may occur once these protective mechanisms have been overcome ${ }^{(10,19,20)}$

Once generated, free radicals can attack many types of molecules, thereby causing damage and rendering them inactive. Photoreceptor cells which possess a dense of cell membranes are particularly vulnerable to free radical's effects; the attack of free radicals on polyunsaturated fatty acids results in lipid peroxidation that breaks down membranous structure ${ }^{(\mathbf{1 8 )}}$. The a-wave reflects the photoreceptor activity.The b-wave is generated in the middle retinal layer in which the blood supply is provided mainly by the retinal circulation. The b-wave amplitude depends on the a-wave, on retinal circulation, and on the functional integrity of the interactions between the a-and b- wave generators (21). Accordingly, the b-wave is believed to be a good indicator of the middle retina and retinal circulation ${ }^{(21)}$. So, this explanation may give an intuitively idea about the deformation obtained in the ERG. Therefore, the accumulation of free radicals after the longest exposure period to blue color may be the reason for the appearance of the negative ERG which reflects the non-vitality of the retina in the form of blocking the signal transmission from photoreceptors to second and higher order retinal neurons ${ }^{(13,22)}$.
Histopathological examination of the rat's retina with light microscope correlates well with these findings. The changes occurred in the rat's retina after exposure to blue LED is in the form of fragmentation of outer segments of photoreceptor, which suffers sever fragmentation and disconnection between outer and inner segments on the $21^{\text {st }}$ day of exposure to blue color where negative ERG was recorded.

Nakanishi-Ueda et al., (2013) ${ }^{(23)}$ reported that the livingretinal pigment epithelium (RPE) cells absorbed blue LED leading to photochemical reaction that generated ROS and resulted in oxidative stress. Oxidative stress is an early step leading to cellular damage by blue LED exposure. In the present study, the significant damage in the pigment epithelium as shown in the light microscope photographs may be followed by a disturbance in the metabolic relationship existing between the retinal layers and the pigment epithelium. This may be followed by a rapid degeneration initially in the photoreceptor outer segments. These effects would eventually appear in the ERG records. Hafezi et al., (1997) (24) used an animal model to determine that excessive exposure to blue light is a critical factor in photochemical retinal injury targeting photoreceptors and the (RPE).

As regard to the middle of the retina, the damage is in the form of swollen nuclei of the bipolar, horizontal, and amacrine cells and their cytoplasm is vacuolated. The damage increases through time of exposure. Under the effect of blue LED light exposure, the results of ERG and the histopathological examinationindicate that they are strongly dependent on both duration of exposure and wavelength of light.

\section{Conclusion}

* Photochemical damage to retinal tissues occurs when the incidance light has a wavelength in the high energy portion of the visible spectrum (blue color).

* The present results suggest that oxidative stress is an early step leading to cellular damage by blue LED exposure.

* The free radicals generated due to high energy light attack polyunsaturated fatty acids which results in lipid peroxidation that breaks down membranous structure, especially in photoreceptor region. 
* The wavelength and time of exposure should be considered carefully when switching to LED lighting applications.

\section{$\underline{\text { References }}$}

1. Boettner, A.E, Wolter, J.R.,'Transmission of the ocular media". Invest Ophthalmol.; 1, 776 - 783, (1962).

2. Tso M.O., "Photic maculopathy in rhesus monkey. A light and electron microscopic study". Invest. Ophthalmol.; 12:17-34, (1973).

3. Parver, L.M, Auker, C.R., Fine, B.S.,"Observations on monkey eyes exposed to light from and operating microscope”. Ophthalmol.,90, 964 - 972, (1983).

4. Godley, B.F., Shamsi, F.A., Liang, F. Q., Jarrett, S. G., Davies, S. and Boulton, M. "Blue light induces mitochondrial DNA damage and free radical production in epithelial cells". J. Biol. Chem.,280, 21061-21066, (2005).

5. Roehlecke, C. Schaller, A., Knels, L. and Funk, R. H "The influence of sublethal blue light exposure on human RPE cells". Mol. Vis.15, 1929-1938,(2009).

6. Holzman, D.C., "What's in a color? The unique human health effect of blue light". Environ. Health Perspect., 118, A22-A27, (2010).

7. Shang, Y.M., Wang, G.S., Sliney, D., Yang, C.H. and Lee, L.L.,"White light-emitting diodes (LEDs) at domestic lighting levels and retinal injury in a rat model". Environ. Health Perspect.,122(3),269-276, (2014).

8. Organisciak, D.andZarbin, M., "Retinal photic injury". Levin LA, Albert DM. Ocular Disease Mechanisms and Management. London: Elsevier, 499-505, (2010).

9. van Norren, D., Gorgels, T.G., "The action spectrum of photochemical damage to the retina: a review of monochromatic threshold data". Photochem. Photobiol., 87(4),747-753, (2011).

10. Dong, A., Shen, J., Krause, M., Akiyama, H., Hackett, S.F., Lai, H., and Campochiaro P.A., "Superoxide dismutase 1 protects retinal cells from oxidative damage". J. Cell Physiol. 208, 516-526, (2006).

11. Wu, J., Seregard, S., Algvere, P.V., "Photochemical damage of the retina". Surv. Ophthalmol. 51, 461481, (2006).

12. Marc, R.E., Jones, B.W., Watt, C.B., VazquezChona, F., Vaughan, D.K., Organisciak, D.T., "Extreme retinal remodeling triggered by light damage: implications for age related macular degeneration”. Mol. Vis. (14), 782-806, (2008).

13. Terasaki, H., Miyake, Y., Mineo, K. and Tanikawa, A., "Focal macular electrorentinogram before and after drainage of macular dubretinalhaemorrhage". American J. of ophth., 123 (12), 207-211, (1997).
14. Roehlecke, C., Schumann, U., Ader, M.., Knels, L., Funk, R.H.,"Influence of blue light on photoreceptors in a live retinal explant system". Mol.Vis., 17, 876-884, (2011).

15. Cai, J., Nelson, K.C., Wu, M., Sternberg, P. Jr, Jones, D.P., "Oxidative damage and protection of the RPE”. Prog. Retin. Eye Res., 19, 205-221, (2000).

16. Liang, F.Q., Godley, B.F., "Oxidative stress-induced mitochondrial DNA damage in human retinal pigment epithelial cells: a possible mechanism for RPE aging and age-related macular degeneration". Exp. EyeRes., 76, 397-403, (2003).

17. Song, J. A., Kim, N. N., Choi, Y. J., Choi, C. Y.,"Effect of green light spectra on the reduction of retinal damage and stress in goldfish, Carassius auratus". Biochemical and Biophysical Research Communications, 476, 96-101, (2016).

18. Youssef, P., Sheibani, N. and Albert, D., "Retinal light toxicity. Eye. 25, 1-14, (2011).

19. Dong, A., Shen, J., Krause, M., Hackett, F., Campochiaro, P., "Increased expression of glial cell line-derived neurotrophic factor protects against oxidative damage-induced retinal degeneration". Journal of Neurochemistry, 103(3), 1041-1052, (2007).

20. Lu, L., Oveson B., Jo Y., Lauer T., Usui S. andKomeima K. "Increased expression of glutathione peroxidase 4 strongly protects retina from oxidative damage". Antioxid Redox Signal, 11(4), 715-724, (2009).

21. Kolb, H., Nelson R., Fernandez, E. and Jones, B., Web vision. "The organization of the retina and visual system". Copyright (C) web vision powered by word press. University of Utah Disclaimer Rhone, M.andA. Basu , 2008.Phytochemicals and age-related eye diseases. Nutr Rev., 66(8), 465-72, (2011).

22. Vinberg, F., Strandman, S. and Koskelainen, A., "Origin of the fast-negative ERG component from isolated aspartate-treated mouse". Retina Journal of Vision, 9 (12), 1-17, (2009).

23. Nakanishi-Ueda, T., Majima, H. J., Watanabe, K., Ueda, T., Indo, H. P., Suenaga, S., Hisamitsu, T., Ozawa, T., Yasuhara, H., and Koide R.,'Blue LED Light Exposure Develops Intracellular Reactive Oxygen Species, Lipid Peroxidation, and Subsequent Cellular Injuries in Cultured Bovine Retinal Pigment Epithelial Cells". Free Radical Research,47(10), 774-80, (2013).

24. Hafezi, F., Marti, A., Munz, K., Reme, C.E.,'Lightinduced apoptosis: differential timing in the retina and pigment epithelium". Exp. Cell Res.,64, 963970, (1997).

Egypt. J. Biophys. Biomed. Engng. Vol., , (2018) 


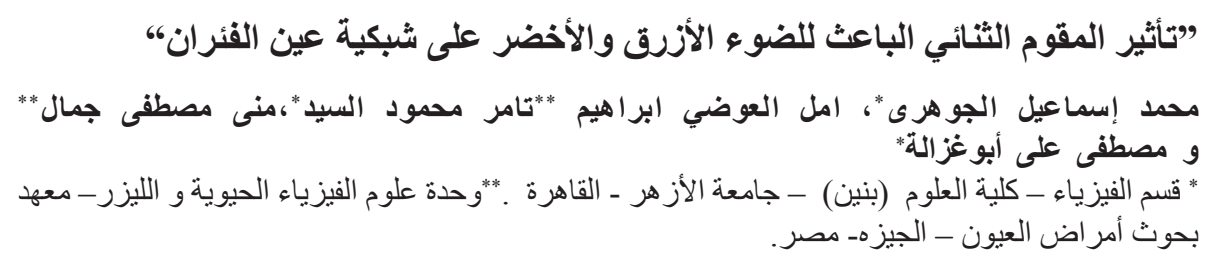

تتعرض أعينتا بشكل متز ايد للضوء المنبعث من المقوم الثنائي الباعث للضوء من محطات عرض الفيديو التى تحتوى على الكثير من الضوء الأزرق. وتجهز محطات عرض الفيديو بأجهزة التليفزيون وأجهزة الكومبيوتر الثخصية وكذاللك الهو اتف المحمولة ولذلك فإنه من الضرورى معرفة الاثار المنرتبة التى تنتج من تعرض الجهاز البصري فى الانسان إلى الإشعاعات المنبعثة من المقوم الثنائي. صمدت هذه الدر اسة لتقييم تأثير المقوم الثنائى الباعث للضوء الأزرق و الأخضر على شبكية عين

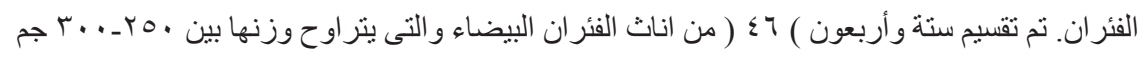
إلى ثلاث مجمو عات ، المجموعة الأولى تمثل المجمو عة الضابطة وتم تعريض المجموعة الثانية للمقوم الثنائى الباعث للضوء الأزرق كما تم تعريض المجموعة الثالثة للمقوم الثنائى الباعث للضوء الأخضر و تقسيمهما لاربعة فتر ات مختلفة وهى ب ، V ، ـ ا و آ يوم ، وفى نهاية كل فترة بتم إجر اء تقنية تسجيل 